\title{
Patient Experiences with Screening and Assistance for Social Isolation in Primary Care Settings
}

\author{
Elizabeth L. Tung, MD, $M S^{7}$ (1) , Emilia H. De Marchis, MD, MAS ${ }^{2}$, \\ Laura M. Gottlieb, MD, MPH', Stacy Tessler Lindau, MD, MAPP ${ }^{3}$, and Matthew S. Pantell, \\ $M D, M S^{4}$
}

\begin{abstract}
'Section of General Internal Medicine, Center for Health and the Social Sciences, and Chicago Center for Diabetes Translation Research, University of Chicago, Chicago, IL, USA; ${ }^{2}$ Department of Family \& Community Medicine, University of California San Francisco, San Francisco, CA, USA;

${ }^{3}$ Department of Obstetrics and Gynecology, Department of Medicine-Geriatrics, Center for Healthcare Delivery Science and Innovation and the Comprehensive Cancer Center, University of Chicago, Chicago, IL, USA; ${ }^{4}$ Department of Pediatrics, Center for Health and Community, University of California San Francisco, San Francisco, CA, USA.
\end{abstract}

BACKGROUND: Social isolation is a known predictor of mortality that disproportionately affects vulnerable populations in the USA. Although experts began to recognize it as a public health crisis prior to 2020 , the novel coronavirus pandemic has accelerated recognition of social isolation as a serious threat to health and well-being.

OBJECTIVE: Examine patient experiences with screening and assistance for social isolation in primary care settings, and whether patient experiences with these activities are associated with the severity of reported social isolation.

DESIGN: Cross-sectional survey conducted in 2018. PARTICIPANTS: Adults $(N=251)$ were recruited from 3 primary care clinics in Boston, Chicago, and San Francisco.

MAIN MEASURES: A modified version of the BerkmanSyme Social Network Index (SNI), endorsed by the National Academies of Sciences, Engineering, and Medicine; items to assess for prior experiences with screening and assistance for social isolation.

KEY RESULTS: In the sample population, $12.4 \%$ reported the highest levels of social isolation ( $\mathrm{SNI}=0 / 1)$, compared to $36.7 \%, 34.7 \%$, and $16.3 \%$ (SNI $=2-4$, respectively). Most patients had not been asked about social isolation in a healthcare setting (87.3\%), despite reporting no discomfort with social isolation screening (93.9\%). Neither discomfort with nor participation in prior screening for social isolation was associated with social isolation levels. Desire for assistance with social isolation (3.2\%) was associated with a higher level of social isolation $(\mathrm{AOR}=6.0$, 95\% CI, 1.3-28.8), as well as poor or fair health status (AOR $=9.1 ; 95 \%$ CI, 1.3-64.1).

CONCLUSIONS: In this study, few patients reported being screened previously for social isolation in a primary care setting, despite low levels of discomfort with screening. Providers should consider broadening social isolation screening and referral practices in healthcare settings, especially among sicker and more isolated patients who express higher levels of interest in assistance with social isolation.

Received June 18, 2020

Accepted December 15, 2020

Published online February 2, 2021
KEY WORDS: social isolation; social risk; social determinants of health; health-related social needs.

J Gen Intern Med 36(7): 1951-7

DOI: $10.1007 / \mathrm{s} 11606-020-06484-9$

(c) Society of General Internal Medicine 2020

\section{INTRODUCTION}

Even before the arrival of COVID-19, social isolation was recognized as a growing health concern. ${ }^{1-3}$ Defined as the objective lack or limitation of contact with others, ${ }^{3}$ social isolation affects approximately one in five older adults, ${ }^{1}$ but can be salient across the life course and heightened during transitional stages. ${ }^{4-6}$ In fact, rates of social isolation across age groups may be increasing, ${ }^{7}$ despite the unprecedented expansion in technological and digital connection. The number of people living alone has more than doubled since 1960, now nearing 30\%. ${ }^{89}$ In parallel, there has been a gradual reduction in American social participation in community organizations, religious groups, and civic life. ${ }^{10}$ A 2020 national survey of over 10,000 working US adults concluded that all age groups reported more loneliness, the subjective feeling of social isolation, ${ }^{3}$ compared to previous years; younger adults aged 18-37 years reported the most loneliness. ${ }^{7}$ This growth in social isolation has been especially alarming as numerous studies have documented strong linkages between social isolation and early mortality. ${ }^{11,12}$ One meta-analysis of 308,849 participants across 148 studies noted that the risk of mortality conferred by social isolation was comparable to smoking 15 cigarettes per day. ${ }^{11}$ The COVID-19 pandemic has accentuated the extensive psychological and physical health effects of social isolation as people worldwide are sheltering in place, many of whom are sheltering alone.

Organizations such as the National Academy of Sciences, Engineering, and Medicine (NASEM), ${ }^{3,13,14}$ American Association of Retired Persons (AARP), ${ }^{1}$ and others have published comprehensive reports describing recommendations for addressing social isolation in the USA. One such recommendation is to implement routine screening and assistance 
for social isolation in healthcare settings. ${ }^{1,3,15}$ John Cacioppo, an early pioneer in the field, advocated for such screening in healthcare ${ }^{15}$; and NASEM has endorsed screening along with incorporating social risk data into electronic health records. ${ }^{13}$ These calls for screening come at a time when the Centers for Medicare \& Medicaid Services and other payors are increasing incentives to screen patients for health-related social risk factors (SRFs). ${ }^{16,17}$ Several national organizations have created standardized instruments for SRF assessment in healthcare settings. These instruments include NASEM's recommended measures ${ }^{13}$ the National Association of Community Health Centers' PRAPARE tool, ${ }^{18}$ and Medicare's Accountable Health Communities social risk screening tool. ${ }^{16,19}$ Only some of these emerging SRF assessments include social isolation as a core measure. Moreover, we are not aware of any studies that have examined current screening practices for social isolation in US primary care settings.

Currently, there is little consensus regarding whom to screen, including whether assistance should be offered broadly or targeted to specific populations. ${ }^{20}$ Prior literature has highlighted financial hardship, ${ }^{21}$ aging, ${ }^{22}$ and violent neighborhood settings ${ }^{23}$ as significantly linked to social isolation and its health consequences. During the 1995 Chicago heatwave, the majority of victims who died were elderly adults who lived alone, could not afford air conditioning, and were isolated to their homes due to fear of violent crime. ${ }^{24}$ Extensive literature has also documented a dialectical relationship between intimate partner violence (IPV), specifically, and social isolation. ${ }^{25,26}$ This relationship has been underscored in light of the COVID-19 crisis, as some victims have had to isolate with an abuser. ${ }^{26}$ Other studies, however, have documented that the consequences of social isolation may also - and even disproportionately - affect populations that are not traditionally considered "high risk." For instance, in a meta-analysis examining 70 prospective studies with 3,407,134 participants, middle-aged adults who were socially isolated had greater risk of mortality than older adults. ${ }^{27}$ Thus, it remains unclear if higher risk is synonymous with higher need, and targeting interventions to those with the greatest need may still rely on some level of screening to identify socially isolated individuals. We also lack information about whether populations at higher risk of social isolation find screening acceptable and would be interested in assistance.

The primary objective of this study was to examine whether patients had prior experiences with screening and assistance for social isolation in primary care settings, and whether discomfort with screening and desire for assistance were associated with the severity of reported social isolation. This analysis used data collected in the context of a multi-site parent study that tested an established set of SRF screening measures endorsed by NASEM, including a modified version of the BerkmanSyme Social Network Index (SNI). ${ }^{14,28}$ In addition to field testing the SNI measure in a diverse clinical sample, the survey assessed experiences with prior screening, discomfort with screening, desire for assistance, and prior assistance related to social isolation. As a secondary objective, to explore whether certain populations may disproportionately benefit from interventions, we assessed associations of other social and demographic risks with participants' levels of social isolation and desire for assistance.

\section{METHODS}

\section{Study Design}

This study used data from a multi-site cross-sectional parent study conducted by the Social Interventions Research \& Evaluation Network (SIREN) that has been described in detail in prior work. ${ }^{29}$ For this analysis, we included data from a sub-study of adult participants $(N=251)$, aged $\geq 18$ years, who completed a one-time survey including the SRF screening items endorsed by NASEM. ${ }^{13,14}$ A convenience sample of adult participants were recruited from 3 academic primary care clinics in Boston, Chicago, and San Francisco; adult caregivers of pediatric patients were also recruited in San Francisco. Participants were included if they were able to provide informed consent, self-complete the survey in English or Spanish, and use a tablet. Participants were excluded if they required immediate medical attention. Eligible participants were randomized to 4 versions of the survey that differed by order of survey items.

\section{Main Measures}

Primary Measures. Surveys included a modified version of the Berkman-Syme SNI, which uses scoring algorithms constructed for the National Health and Nutrition Examination Survey (NHANES). ${ }^{12,28}$ NASEM's selection of the SNI is described in their 2014 report and was based on feasibility of implementation in busy clinical settings and its strong association with health outcomes. ${ }^{14}$ In a previous study of 16,849 adult participants in NHANES III between the ages of 17 and 89 years, SNI scores successfully predicted mortality in a nationally representative population. ${ }^{12}$ Participants were asked about the following social network characteristics: frequency of interaction with social networks, social participation, and marital or relationship status (Appendix Table 1). SNI scores ranged from 0 to 4 , with 0 representing a low SNI (highest level of social isolation) and 4 representing a high SNI (lowest level of social isolation). Scores of 0 and 1 were collapsed into a single category due to similar scoring conventions in previous studies. ${ }^{12}$ Full psychometric details of the measure can be found in previously published work. ${ }^{12,28}$

Additional survey items were developed to assess for prior experiences with screening and assistance for social isolation: prior screening in the last 12 months, discomfort with screening, desire for assistance, and prior assistance in the last 12 months (Appendix Table 1). ${ }^{29}$ 
Secondary Measures. Survey items assessing other social risks were derived from published sources and endorsed by NASEM, as described in their 2014 report. ${ }^{13,14}$ Financial strain was measured using the single item ("How hard is it for you to pay for the very basics like food, housing, medical care, and heat?"), ${ }^{14,30}$ with a 3 -item response ranging from "very hard" to "not hard at all." This item was recommended by NASEM after review of Kahn and Pearlin's validation studies ${ }^{14,30}$ and two large national surveys documenting the validity of a single-item measure. ${ }^{31,32}$ IPV was measured using the HARK (Humiliation, Afraid, Rape, and Kick) screening tool, ${ }^{33}$ a 4-item measure. At least one "yes" answer indicated a positive screen. This item was recommended by NASEM based on pragmatic implementation ${ }^{14}$ and high specificity for IPV. The sensitivity and specificity for a positive screen are $81 \%$ and $95 \%$, respectively. ${ }^{34}$

\section{Statistical Analysis}

Descriptive statistics were calculated for clinic location, selfreported health status, and sociodemographic characteristics, including age, gender, race/ethnicity, and educational attainment. These statistics were also stratified by participants' prior experiences with screening and assistance for social isolation. Fisher's exact test of independence was used to detect significant differences $(p<0.05)$. We used unadjusted and adjusted ordinal logistic regression models to examine SNI levels as a function of screening and assistance experiences (prior screening, discomfort with screening, desire for assistance, prior assistance), adjusting for all aforementioned participant characteristics. In primary models, the approximate likelihoodratio test for proportionality of odds ranged from a chisquared value of 11.43 to 21.11 . We observed no violations of the proportional odds assumption to a $p$ value $<0.05$.

For primary measures of interest, including SNI and prior experiences with screening and assistance, data were complete because variable construction accounted for non-response. ${ }^{28}$ Thirty-eight participants (15.1\%) had missing values for at least 1 covariate. We observed no statistically significant differences in missing covariate data across primary dependent and independent measures of interest (Appendix Table 2). However, to address potential concerns regarding missing data, we conducted a sensitivity test (Appendix Table 3) using multiple imputation analysis (20 imputations). Data analysis was conducted in 2019-2020 using Stata, version 15.0 (College Station, TX).

\section{RESULTS}

The majority of participants were middle-aged and older (56.9\%), female (65.3\%), and completed at least some college $(58.1 \%)$. There were similar numbers of non-Hispanic White (28.7\%), non-Hispanic Black (27.1\%), and Hispanic/Latino participants (31.1\%; Table 1). Overall, $12.4 \%$ of participants reported the highest level of social isolation $(\mathrm{SNI}=0 / 1)$,
Table 1 Participant Characteristics, NASEM Screening Instrument, 2018

\begin{tabular}{lll}
\hline \hline Participant characteristics, $N=\mathbf{2 5 1}$ & no. & \% \\
\hline Clinic location & & \\
San Francisco & 100 & 39.8 \\
Chicago & 100 & 39.8 \\
Boston & 51 & 20.3 \\
Age (years) & 93 & \\
18-44 & 96 & 37.1 \\
45-64 & 47 & 38.2 \\
65 and older & 15 & 18.7 \\
No response & & 6.0 \\
Gender & 74 & 29.5 \\
Male & 164 & 65.3 \\
Female & 13 & 5.2 \\
No response & 72 & \\
Race/ethnicity & 68 & 28.7 \\
White non-Hispanic & 78 & 27.1 \\
Black non-Hispanic & 14 & 31.1 \\
Hispanic or Latino & 19 & 5.6 \\
Other & 7.6 \\
No response & 24 & \\
Educational attainment (highest level completed) & \\
Less than high school (1-8 years) & 81 & 32.3 \\
High school (9-12 years) & 95 & 37.8 \\
College (13-16 years) & 49 & 19.5 \\
More than college (17 or more years) & 2 & 0.8 \\
No response & & \\
Self-reported health & 30 & 12.0 \\
Excellent & 68 & 27.1 \\
Very good & 73 & 29.1 \\
Good & 47 & 18.7 \\
Fair & 19 & 7.6 \\
Poor & 14 & 5.6 \\
No response & & \\
\hline
\end{tabular}

compared to $36.7 \%(\mathrm{SNI}=2), 34.7 \%(\mathrm{SNI}=3)$, and $16.3 \%$ $(\mathrm{SNI}=4$; lowest level) at each respective level.

Most participants had not been asked previously about social isolation in a healthcare setting $(87.3 \%)$. The majority reported no discomfort with the social isolation screening measure $(93.9 \%)$. Few reported previously receiving assistance $(3.8 \%)$ or having a desire for assistance with social isolation $(2.8 \%$; Table 2$)$. However, having previously received assistance was significantly associated with being asked about social isolation in the past 12 months $(p=0.001$; Fig. 1). Among those who received assistance, more than half $(62.5 \%)$ were asked about social isolation in the past 12 months, compared to fewer $(10.7 \%)$ who were asked but did not receive assistance.

Sociodemographic characteristics were not associated with prior screening for social isolation (Table 2). There were significant differences in discomfort with screening based on education, with those who attained less than a high school education endorsing the most discomfort $(p=0.04)$, although only $6.1 \%$ of participants $(n=13)$ reported discomfort overall. While only $2.8 \%$ of participants reported a desire for assistance overall, $9.3 \%$ of those reporting fair or poor health desired assistance compared to $0.6 \%$ of those with good or better health $(p=0.004)$. A higher level of social isolation was associated with a desire for assistance (adjusted odds ratio $[\mathrm{AOR}]=6.0,95 \% \mathrm{CI}, 1.3-28.8$; Table 3). In multiple imputation analyses, results remained substantively similar (Appendix Table 3). 
Table 2 Association of Participants' Social and Demographic Characteristics with Experiences of Screening and Assistance for Social Isolation

\begin{tabular}{|c|c|c|c|c|c|c|c|c|}
\hline \multirow[t]{2}{*}{ Participant characteristics, $N=213^{\mathrm{a}}$} & \multicolumn{2}{|c|}{$\begin{array}{l}\text { Prior screening for } \\
\text { social isolation (last } \\
12 \text { months) }\end{array}$} & \multicolumn{2}{|c|}{$\begin{array}{l}\text { Discomfort with } \\
\text { screening for social } \\
\text { isolation }\end{array}$} & \multicolumn{2}{|c|}{$\begin{array}{l}\text { Desire for } \\
\text { assistance with } \\
\text { social isolation }\end{array}$} & \multicolumn{2}{|c|}{$\begin{array}{l}\text { Prior assistance } \\
\text { with social isolation } \\
\text { (last } 12 \text { months) }\end{array}$} \\
\hline & $\%$ & $p$ value $^{\mathrm{b}}$ & $\%$ & $p$ value $^{\mathrm{b}}$ & $\%$ & $p$ value $^{\mathrm{b}}$ & $\%$ & $p$ value $^{\mathrm{b}}$ \\
\hline \multicolumn{9}{|l|}{ Clinic Location } \\
\hline San Francisco & 15.7 & 0.54 & 5.6 & 0.26 & 4.5 & 0.51 & 6.7 & 0.21 \\
\hline Chicago & 11.4 & & 3.8 & & 1.3 & & 1.3 & \\
\hline Boston & 8.9 & & 11.1 & & 2.2 & & 2.2 & \\
\hline \multicolumn{9}{|l|}{ Age (years) } \\
\hline $18-44$ & 11.1 & 0.74 & 6.7 & 0.33 & 4.4 & 0.50 & 3.3 & 0.06 \\
\hline $45-64$ & 13.3 & & 3.6 & & 1.2 & & 1.2 & \\
\hline 65 and older & 15.0 & & 10.0 & & 2.5 & & 10.0 & \\
\hline \multicolumn{9}{|l|}{ Gender } \\
\hline Male & 13.3 & 0.82 & 5.0 & 1.00 & 1.7 & 1.00 & 5.0 & 0.69 \\
\hline Female & 12.4 & & 6.5 & & 3.3 & & 3.3 & \\
\hline \multicolumn{9}{|l|}{ Race/ethnicity } \\
\hline White non-Hispanic & 12.1 & 0.12 & 10.6 & 0.25 & 1.5 & 0.72 & 1.5 & 0.35 \\
\hline Black non-Hispanic & 7.8 & & 3.1 & & 4.7 & & 3.1 & \\
\hline Hispanic or Latino & 14.1 & & 4.2 & & 2.8 & & 5.6 & \\
\hline Other & 33.3 & & 8.3 & & 0 & & 8.3 & \\
\hline \multicolumn{9}{|l|}{ Education (highest level attained) } \\
\hline College or more (13 or more years) & 12.5 & 0.82 & 7.0 & 0.04 & 2.3 & 0.66 & 3.1 & 0.02 \\
\hline High school ( $9-12$ years) & 11.9 & & 1.5 & & 4.5 & & 1.5 & \\
\hline Less than high school (1-8 years) & 16.7 & & 16.7 & & 0 & & 16.7 & \\
\hline \multicolumn{9}{|l|}{ Self-reported health } \\
\hline Excellent, very good, or good & 11.3 & 0.35 & 5.0 & 0.32 & 0.6 & 0.004 & 2.5 & 0.12 \\
\hline Fair or poor & 16.7 & & 9.3 & & 9.3 & & 7.4 & \\
\hline \multicolumn{9}{|l|}{ Financial strain } \\
\hline No & 10.9 & 0.41 & 6.9 & 0.78 & 1.0 & 0.21 & 1.0 & 0.07 \\
\hline Yes & 15.1 & & 5.7 & & 4.7 & & 6.6 & \\
\hline \multicolumn{9}{|l|}{ Intimate partner violence } \\
\hline Negative HARK & 11.4 & 0.30 & 4.4 & 0.27 & 2.2 & 0.42 & 3.8 & 1.0 \\
\hline Positive HARK & 19.1 & & 9.5 & & 4.8 & & 0 & \\
\hline Overall & 12.7 & - & 6.1 & - & 2.8 & - & 3.8 & - \\
\hline
\end{tabular}

${ }^{a}$ Included only participants with no missing values

${ }^{b}$ Calculated using Fisher's exact test of independence

Several social and demographic characteristics were associated with a higher level of social isolation (Appendix Table 4): older age (45-64 years: AOR $=2.0,95 \%$ CI, $1.1-$ 3.6 ; $\geq 65$ years: $\mathrm{AOR}=3.0,95 \% \mathrm{CI}, 1.4-6.6$ ), difficulty paying for material needs $(\mathrm{AOR}=2.0 ; 95 \% \mathrm{CI}, 1.0-3.7)$, and safety concerns due to IPV (AOR $=2.7 ; 95 \% \mathrm{CI}, 1.1-6.9)$.

\section{DISCUSSION}

We report low rates of screening and assistance for social isolation in a sample of US adults from primary care settings. This is one of the first studies, of which we are aware, to report on healthcare activities related to social isolation. Among adults seeking care for themselves or a child at primary care clinics in Boston, Chicago, and San Francisco, only 12.7\% reported being screened for social isolation in the past year, despite low levels of discomfort with screening. Similarly, only $3.6 \%$ of participants reported receiving assistance for social isolation in the past year. These findings suggest that there is not yet robust integration of social isolation assessment and assistance in these urban clinical care practices, even though national organizations have recommended incorporating social isolation status into electronic health records. ${ }^{3}$ Given high rates of patient acceptability, clinical practices might consider increasing social isolation screening and assistance as

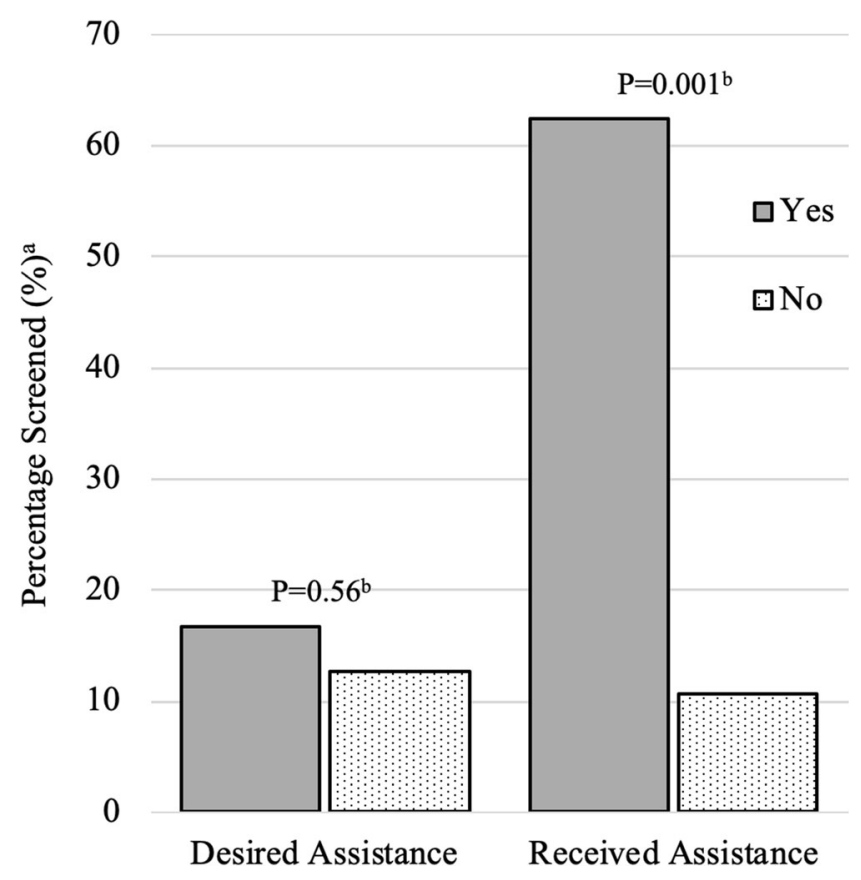

Figure 1 Association between screening and assistance for social isolation. ${ }^{\text {a}}$ Percentage of participants who were asked about social isolation in the past 12 months. ${ }^{b} p$ values derived using Fisher's exact tests. NOTE: Each bar describes the percentage of participants who were screened for social isolation out of all participants who responded "yes" or "no" to each assistance item. For instance, of all participants who responded "yes" to receiving prior assistance for social isolation, $\mathbf{6 2 . 5 \%}$ were screened in the past 12 months. 
Table 3 Association of Participants' Prior Experiences of Screening and Assistance for Social Isolation with Social Network Index (SNI)

\begin{tabular}{|c|c|c|c|c|c|c|c|}
\hline \multirow{2}{*}{$\begin{array}{l}\text { Prior experiences with screening } \\
\text { andassistance, } \\
N=\mathbf{2 1 3}^{\mathrm{a}}\end{array}$} & & \multicolumn{4}{|c|}{$\begin{array}{l}\text { Social network index } \\
\text { [SNI] }(\%)\end{array}$} & \multicolumn{2}{|c|}{$\begin{array}{l}\text { Odds of social isolation } \\
\text { (per unit reduction in SNI) }\end{array}$} \\
\hline & & Most isolated, $0 / 1$ & 2 & 3 & Least isolated, 4 & OR $(95 \%$ CI $)$ & $\begin{array}{l}\text { Adjusted OR } \\
(95 \% \mathrm{CI})^{\mathrm{b}}\end{array}$ \\
\hline $\begin{array}{l}\text { Prior screening for social isolation } \\
\text { (last } 12 \text { months) } \\
\text { Discomfort with screening for } \\
\text { social isolation } \\
\text { Desire for assistance with } \\
\text { social isolation } \\
\text { Prior assistance with social isolation } \\
\text { (last } 12 \text { months) }\end{array}$ & $\begin{array}{l}\text { No } \\
\text { Yes } \\
\text { No } \\
\text { Yes } \\
\text { No } \\
\text { Yes } \\
\text { No } \\
\text { Yes }\end{array}$ & $\begin{array}{l}11.3 \\
14.8 \\
11.0 \\
23.1 \\
11.1 \\
33.3 \\
12.2 \\
0\end{array}$ & $\begin{array}{l}37.1 \\
22.2 \\
35.0 \\
38.5 \\
34.8 \\
50.0 \\
35.6 \\
25.0\end{array}$ & $\begin{array}{l}33.9 \\
44.4 \\
36.0 \\
23.1 \\
35.8 \\
16.7 \\
34.2 \\
62.5\end{array}$ & $\begin{array}{l}17.7 \\
18.5 \\
18.0 \\
15.4 \\
18.4 \\
0 \\
18.1 \\
12.5\end{array}$ & $\begin{array}{l}\text { Ref } \\
0.80(0.38-1.67) \\
\text { Ref } \\
1.91(0.66-5.55) \\
\text { Ref } \\
4.74(1.08-20.78) * * \\
\text { Ref } \\
0.59(0.18-1.92)\end{array}$ & $\begin{array}{l}\text { Ref } \\
0.66(0.30-1.43) \\
\operatorname{Ref} \\
1.71(0.56-5.27) \\
\operatorname{Ref} \\
6.04(1.26-28.84)^{* *} \\
\operatorname{Ref} \\
0.32(0.08-1.18)^{*}\end{array}$ \\
\hline
\end{tabular}

${ }^{a}$ Included only participants with no missing covariate data

${ }^{b}$ Ordinal logistic regression models adjusted for age, gender, educational attainment, racelethnicity, self-reported health status, and clinic *p $<0.10$, $* * p<0.05 ; C I$, confidence interval

part of a more comprehensive strategy to improve patient health and well-being. The COVID-19 pandemic is also likely to increase the prevalence, severity, and health impact of social isolation across the USA, making these types of activities increasingly important.

There are several possible explanations for low rates of screening. First, we observed that more isolated patients were not more likely to report being asked about social isolation. It is possible that clinicians do not reliably identify patients who are more isolated and in need of help, or may underestimate the amount of help that is needed. ${ }^{35} \mathrm{~A}$ second possibility is that clinicians may be uncomfortable with screening in the absence of resources that can support individuals who are socially isolated. For instance, a clinician may know that an elderly woman has outlived many of her close friends and family members. However, without knowledge of any resources available to her, a clinician can feel helpless to address these challenges and may be concerned about the implications of screening without a direct path to assistance (e.g., healthcare liability, patient stigma). ${ }^{36}$ In the UK, a Minister for Loneliness was appointed in 2017 to begin a social prescribing program and launched a national platform for clinicians to share and retrieve resources that address social isolation. ${ }^{37}$ NASEM has recommended that the US Department of Health and Human Services should similarly fund a national platform to centralize resources, training, and best practices for social isolation. ${ }^{3}$ Although local databases are emerging, ${ }^{19,38,39}$ availability continues to vary dramatically by geography. This variability in available databases, as well as the difficulty of accessing in-person resources due to COVID-19, highlights the need for centralized and easily-accessible resource databases that compile high-quality information about social isolation-targeted interventions.

While programs to improve connections to social risk resources are critical, prior qualitative literature has documented benefits to screening beyond the direct provision of resources. In a prior study, we noted that patients often appreciated acknowledgement and discussion of social risks, even in the absence of a concrete intervention. ${ }^{40}$ Inquiring about social isolation may thereby benefit the patient-provider relationship. It is also cornerstone to social risk-informed care, which refers to adjusting patient care to be more appropriate or better suited for a patient's social context. ${ }^{17,39}$ The opportunity to provide support, outside of resolving the social isolation itself, may provide encouragement to clinicians who feel they have no resources to offer.

It is notable that while most patients had no discomfort with social isolation screening, they also reported low levels of interest in assistance. We suspect that interest in assistance may increase as screening becomes more common and patients begin to think about social isolation as relevant to their health. ${ }^{29}$ In addition, we did find that those who reported fair or poor health expressed higher levels of interest in assistance. These findings are consistent with prior literature documenting that adults who had high medical needs were at especially high risk for social isolation. ${ }^{41}$ In this vulnerable population, isolation can make it harder to manage health, which can in turn drive worsening feelings of isolation. In resource-constrained settings, narrowing screening initiatives to these patients may help to target interventions to those with the greatest need and desire for assistance with social isolation.

Finally, we found significant associations between high levels of social need, including both financial strain and IPV, and high levels of isolation. These findings are consistent with existing literature linking both poverty and violence with social exclusion more generally. ${ }^{21,42}$ Moreover, these types of social risks can often intersect, further exacerbating adverse health effects. Ongoing assessment is warranted to elucidate how interventions may target these risk factors together. For instance, it is possible that IPV interventions are less effective when victims are socially isolated. Alternatively, IPV may exacerbate social isolation, and approaches to addressing social isolation in this population may require multifaceted approaches. Multi-domain social risk screening is one way to identify those at highest risk for poor outcomes.

This study has several limitations. First, as the study sample was limited to three academic primary care clinics in Boston, Chicago, and San Francisco, findings are most generalizable 
to US urban-dwelling adults receiving care in academic settings. Second, this was a cross-sectional analysis, limiting causal inference. Third, the study sample was relatively small and responses were self-reported. It is possible that patients were screened in the past but simply did not remember or did not realize they were being screened. Similarly, they may have been assisted with social isolation in the past but did not realize the intervention was related to social isolation. Additionally, the SNI scale measures the frequency of interaction with social networks, but does not measure the quality of interaction; similarly, it does not distinguish between the types of social participation that participants engage in. ${ }^{28}$ Surveys were completed on tablets which may have contributed to some selection bias for individuals with higher technological proficiency. Selection bias may have also occurred if marginalized populations who declined to participate in the survey were also more likely to decline screening, although few (7.2\%) declined participation overall. While we adjusted for sociodemographic confounders, we were unable to account for certain neighborhood factors, such as access to public transportation or built environment resources. Finally, although multiple imputation did not substantively change the results, it is likely that some items were not missing at random.

\section{CONCLUSIONS}

Social isolation is a growing public health concern with serious implications for both mental and physical health. These implications are most severe for marginalized populations and increasingly salient in light of the COVID-19 pandemic, which has revealed at scale the devastating psychological and physical health effects of social isolation. In addition to its effects on early mortality, social isolation can have adverse effects on quality of life by impeding lifestyle and disease management activities, ${ }^{23}$ maintaining depression, or promoting cognitive decline. ${ }^{43}$ These adverse effects can, in turn, increase social isolation. Despite accelerating awareness that social isolation can have far-reaching implications for health, few healthcare settings have integrated social isolation activities into practice. This study documents low rates of screening for social isolation in a sample of patients from primary care clinics, even though patients express little discomfort with screening. Future work should explore strategies to support clinical screening and interventions related to social isolation.

Supplementary Information The online version contains supplementary material available at https://doi.org/10.1007/s11606-02006484-9.

Corresponding Author: Elizabeth L. Tung, MD, MS; Section of General Internal Medicine, Center for Health and the Social Sciences, and Chicago Center for Diabetes Translation Research, University of Chicago, Chicago, IL, USA (e-mail: eliztung@uchicago.edu).
Author Contributions Respective author contributions are as follows. Study concept and design: All authors. Acquisition of data: E.L.T., E.H.D., L.M.G., S.T.L. Analysis and interpretation of data: All authors. Drafting of the manuscript: All authors. Critical revision of the manuscript for important intellectual content: All authors. Obtaining funding: L.M.G. Administrative, technical or material support: E.H.D., L.M.G., S.T.L. Final approval of the version to be published: All authors.

Funding Publication of this article was supported by the Agency for Healthcare Research and Quality (AHRQ), under HHS contract (1R13HSO26664), Kaiser Permanente (CRN5374-7544-15320), and the Robert Wood Johnson Foundation (75922). Dr. Tung was supported by an NIH/NHLBI career development grant (1K23HL145090-01) in patient-oriented research. Dr. Lindau was supported by NIH/NIA (RO1AG064949, RO1M 012630, and R01AG047869). Dr. Pantell was supported by an NIH/LRP award (1L60MD013257-01), AHRQ career development grant (K12HSO26383), and National Center for Advancing Translational Sciences grant (KL2TROO1870).

\section{Compliance with Ethical Standards:}

The study was approved by the University of California San Francisco IRB (17-23,110); the 2 additional study sites also obtained sitespecific IRB approvals.

Conflict of Interest: Dr. Lindau directed a Center for Medicare and Medicaid Innovation Health Care Innovation Award (1C1CMS33099703) called CommunityRx. This award required the development of a sustainable business model to support the model test after award funding ended. To this end, Dr. Lindau is the founder and co-owner of NowPow, LLC. Neither entity is supported through CMS funding. Neither the University of Chicago nor the University of Chicago Medicine endorses or promotes any NowPow Entity or its business, products, or services. The remaining authors declare no conflicts of interest.

Disclaimer: The findings and conclusions in this article are those of the authors and do not necessarily represent the official position of any of the sponsors.

\section{REFERENCES}

1. Elder K, Retrum J. Framework for isolation in adults over 50 . Washington, D.C.: AARP Foundation, 2012.

2. Klinenberg E. Social isolation, loneliness, and living alone: identifying the risks for public health. Am J Public Health. 2016;106(5):786-7.

3. Board on Health Sciences Policy. The Health and Medical Dimensions of Social Isolation and Loneliness in Older Adults Washington, D.C.: National Academy of Medicine; 2020 [January 22, 2020]. Available from: https://www.nationalacademies.org/our-work/the-health-and-medicaldimensions-of-social-isolation-and-loneliness-in-older-adults.

4. Hawkley LC, Capitanio JP. Perceived social isolation, evolutionary fitness and health outcomes: a lifespan approach. Philos Trans R Soc Lond B Biol Sci. 2015;370(1669): 1-12.

5. Qualter $\mathbf{P}$, Vanhalst $\mathbf{J}$, Harris $\mathbf{R}$, et al. Loneliness across the life span. Perspect Psychol Sci. 2015;10(2):250-64.

6. Luhmann M, Hawkley LC. Age differences in loneliness from late adolescence to oldest old age. Dev Psychol. 2016;52(6):943-59.

7. Cigna Behavioral Health. Loneliness and the Workplace: 2020 U.S. Report. 2020. Available from: https://www.cigna.com/about-us/newsroom/studies-and-reports/combatting-loneliness/.

8. Klinenberg E. The extraordinary rise and surprising appeal of living alone. New York, NY: The Penguin Press 2012.

9. U.S. Census Bureau. The rise of living alone Washington, D.C. 2019 [January 9, 2020]. Available from: https://www.census.gov/content/ dam/Census/library/visualizations/time-series/demo/families-andhouseholds/hh-4.pdf. 
10. Putnam RD. Bowling alone: the collapse and revival of American community. New York: Simon \& Schuster 2000.

11. Holt-Lunstad J, Smith TB, Layton JB. Social relationships and mortality risk: a meta-analytic review. PLoS Med. 2010;7(7):e1000316.

12. Pantell M, Rehkopf D, Jutte D, et al. Social isolation: a predictor of mortality comparable to traditional clinical risk factors. Am J Public Health. 2013;103(11):2056-62.

13. Committee on the Recommended Social and Behavioral Domains and Measures for Electronic Health Records; Board on Population Health and Public Health Practice; Institute of Medicine. Capturing Social and Behavioral Domains and Measures in Electronic Health Records: Phase 1. Washington, D.C.: The National Academies Press; 2014 Jun 23.

14. Committee on the Recommended Social and Behavioral Domains and Measures for Electronic Health Records; Board on Population Health and Public Health Practice; Institute of Medicine. Capturing Social and Behavioral Domains and Measures in Electronic Health Records: Phase 2. Washington, D.C.: The National Academies Press; 2015 Jan 8.

15. Cacioppo JT, Cacioppo S. The growing problem of loneliness. Lancet. 2018;391(10119):426.

16. Center for Medicare and Medicaid Innovation. The Accountable Health Communities Health-Related Social Needs Screening Tool 2018 [March 18, 2020]. Available from: https://innovation.cms.gov/files/ worksheets/ahcm-screeningtool.pdf.

17. Alderwick H, Gottlieb LM. Meanings and misunderstandings: a social determinants of health lexicon for health care systems. Milbank Q. 2019;97(2):407-19

18. National Association of Community Health Centers, Association of Asian Pacific Community Health Organizations, Association of OPC, et al. The Protocol for Responding to and Assessing Patients' Assets, Risks, and Experiences (PRAPARE) 2016 [April 14, 2020]. Available from: http:// www.nachc.org/research-and-data/prapare/.

19. Alley DE, Asomugha CN, Conway PH, et al. Accountable Health Communities-addressing social needs through medicare and medicaid. N Engl J Med. 2016;374(1):8-11.

20. Klinenberg E. Is Loneliness a Health Epidemic? The New York Times [Internet]. 2018 January 30, 2019. Available from: https://www.nytimes. com/2018/02/09/opinion/sunday/loneliness-health.html.

21. Cattell v. Poor people, poor places, and poor health: the mediating role of social networks and social capital. Soc Sci Med. 2001;52(10):1501-16.

22. Hawkley LC, Cacioppo JT. Aging and loneliness: downhill quickly? Curr Direct Psychol Sci. 2007;16(4):187-91.

23. Tung EL, Hawkley LC, Cagney KA, et al. Social isolation, loneliness, and violence exposure in urban adults. Health Aff (Millwood). 2019;38(10): 1670-8.

24. Klinenberg E. Heat wave: a social autopsy of disaster in Chicago. Chicago, IL: University of Chicago Press 2002: 328 p.

25. Coohey C. The relationship between mothers' social networks and severe domestic violence: a test of the social isolation hypothesis. Violence Vict. 2007;22(4):503-12.

26. van Gelder N, Peterman A, Potts A, et al. COVID-19: Reducing the risk of infection might increase the risk of intimate partner violence. EClinicalMedicine. 2020;21:100348.

27. Holt-Lunstad J, Smith TB, Baker M, et al. Loneliness and social isolation as risk factors for mortality: a meta-analytic review. Perspect Psychol Sci. 2015;10(2):227-37.

28. Berkman LF, Syme SL. Social networks, host resistance, and mortality: a nine-year follow-up study of Alameda County residents. Am J Epidemiol. 1979;109(2):186-204.
29. De Marchis EH, Hessler D, Fichtenberg C, et al. Part I: a quantitative study of social risk screening acceptability in patients and caregivers. Am J Prev Med. 2019;57(6s 1):S25-s37.

30. Kahn JR, Pearlin LI. Financial strain over the life course and health among older adults. J Health Soc Behav. 2006;47(1):17-31

31. Hall MH, Matthews KA, Kravitz HM, et al. Race and financial strain are independent correlates of sleep in midlife women: the SWAN sleep study. Sleep. 2009;32(1):73-82.

32. Puterman E, Haritatos J, Adler NE, et al. Indirect effect of financial strain on daily cortisol output through daily negative to positive affect index in the Coronary Artery Risk Development in Young Adults Study. Psychoneuroendocrinology. 2013;38(12):2883-9.

33. Sohal H, Eldridge S, Feder G. The sensitivity and specificity of four questions (HARK) to identify intimate partner violence: a diagnostic accuracy study in general practice. BMC Fam Pract. 2007;8:49.

34. Nelson HD, Bougatsos C, Blazina I. Screening women for intimate partner violence: a systematic review to update the U.S. Preventive Services Task Force recommendation. Ann Intern Med. 2012;156(11):796-808, w-279, w-80, w-81, w-82.

35. Tong ST, Liaw WR, Kashiri PL, et al. Clinician experiences with screening for social needs in primary care. J Am Board Fam Med. 2018;31(3):351-63.

36. Garg A, Boynton-Jarrett R, Dworkin PH. Avoiding the unintended consequences of screening for Social Determinants of Health. JAMA. 2016;316(8):813-4.

37. Government of the United Kingdom. A Connected Society: A strategy for tackling loneliness. London, UK: Department for Digital, Culture, Media and Sport; 2018 Oct 15. [January 16, 2020] Available from: https:// assets.publishing.service.gov.uk/government/uploads/system/uploads/attachment_data/file/936725/6.4882_DCMS_Loneliness_Strategy_web_Update_V2.pdf.

38. Lindau ST, Makelarski J, Abramsohn E, et al. CommunityRx: a population health improvement innovation that connects clinics to communities. Health Aff (Millwood). 2016;35(11):2020-9.

39. National Academies of Sciences E, Medicine, Health, et al. Integrating Social Care into the Delivery of Health Care: Moving Upstream to Improve the Nation's Health. Washington (DC): National Academies Press (US) Copyright 2019 by the National Academy of Sciences. All rights reserved.; 2019

40. Byhoff E, De Marchis EH, Hessler D, et al. Part II: a qualitative study of social risk screening acceptability in patients and caregivers. Am J Prev Med. 2019;57(6s1):S38-s46.

41. Ryan J, Abrams MK, Doty MM, et al. How High-Need Patients Experience Health Care in the United States. The Commonwealth Fund. 2016 December 9

42. Browning CR, Cagney KA. Moving beyond poverty: neighborhood structure, social processes, and health. J Health Soc Behav. 2003;44(4):552-71.

43. Cacioppo JT, Hawkley LC. Perceived social isolation and cognition. Trends Cogn Sci. 2009;13(10):447-54.

Publisher's Note: Springer Nature remains neutral with regard to jurisdictional claims in published maps and institutional affiliations. 